\title{
Concierto Barroco: Literatura peruana y gastronomía
}

\section{José Güich Rodríguez}

En el presente trabajo, pretendemos brindar un sucinto panorama de la impronta gastronómica en la literatura peruana. Dado que nos enfrentamos a un complejo corpus y, en muchos casos, de difícil acceso, hemos decidido concentrar nuestra atención en un número limitado de textos y autores. No partiremos de obras articuladas en torno de la gastronomia propiamente dicha, sino que abordaremos el asunto desde el ámbito de los grandes referentes literarios. Aunque existe mucha producción de interés, esta pertenece, en su mayoria, a autores menores, y siguiendo al gran poligrafo mexicano Alfonso Reyes, son voces que representan una voluntad meramente ancilar (1).

\section{1}

Para iniciar este derrotero, nos remontaremos al período fundacional de la cultura peruana, es decir, al siglo XVI, que marca el instante crucial en la forja de un pais y un continente mestizos. Nadie mejor que el Inca Garcilaso de la Vega -considerado el precursor no tanto de una nacionalidad, sino de un espíritu que sintetiza diversas experiencias vitales e históricaspara graficar la primera gran irrupción de los alimentos como objetos que se afilian o adquieren carta de ciudadanía en un universo literario.

(1) Reyes propuso el vocablo para un tipo de texto que, sin objetivos meramente estéticos o poéticos, se valen de recursos y estructuras literarias para otorgarle forma a sus intereses particulares
No debe obviarse la singularidad que el Inca exterioriza en una obra de la envergadura de los Comentarios Reales. Hijo de un militar español de ilustres ancestros, asumió la condición de hombre de su tiempo, dotado de una cultura humanistica y renacentista formidable aun para los estándares de su época-. Por el lado materno, descendía nada menos que de la familia imperial. Su madre, Isabel Chimpu Ocllo, había sido sobrina nieta de Huayna Cápac, el último gran soberano del imperio. Desde su exilio cordobés, que se prolongaría durante casi medio siglo, el Inca reconstruyó un mundo perdido para siempre -el de su noble estirpe cusqueña-, y lo integró con maestría al decurso de la historia occidental, de la cual también se sentía heredero y partícipe.

Es cierto que no elaboró una visión absolutamente objetiva de los acontecimientos que transmitiría a la posteridad -tarea casi imposible-; además, resulta innegable que idealizó la organización política y social de los incas, amoldándolos a los usos historiográficos y a los dogmas religiosos que justificaban la conquista de América desde la óptica de los centros de poder europeos. Pero también es una verdad insoslayable que el Inca desempeñó un rol de auténtico pionero en una serie de campos del quehacer intelectual. No es este el espacio indicado para resaltar la envergadura de semejantes contribuciones. 
Desde las primeras páginas de su Comentarios, el Inca proporciona información valiosa sobre los productos y hábitos alimenticios. Sus exposiciones iniciales dan cuenta de las costumbres desarrolladas por los habitantes más antiguos de estas tierras. Un ejemplo concreto lo constituye un capitulo dedicado exclusivamente al tema:

En otras fueron en su comer y manjares tan fieros y bárbaros que pone admiración tanta fiereza, y en otras muchas regiones muy largas tuvieron lo uno y lo otro juntamente(...) En muchas provincias fueron amicissimos de carne humana, y tan golosos que antes que acabasse de morir el indio que mataban le bebian la sangre por la herida que le havian dado, y lo mismo hacian cuando lo ivan descuartizando, que chupavan la sangre y se lamian las manos por que no se perdiese gota de ella. Tuvieron carnecerias públicas de carne humana; de las tripas hazian morcillas y longanizas, hinchéndolas de carne por no perderlas (2).

¿Cuánto de verdad e imaginación nutren semejante episodio? Después de este relato, el Inca cita a Pedro Cieza de León como testigo presencial de dichas prácticas. Recurre a una autoridad en la materia para fortalecer el testimonio. No hay seguridad absoluta acerca de si aquellos gentiles conocieron la técnica de preparación de embutidos -alimentos de vieja data en las mesas europeas-.

La explicación plausible es que -como sucede en innumerables pasajes de la obra- el escritor recurre a analogias o a similes para describir objetos o hábitos desconocidos en las sociedades occidentales de aquel periodo. Pero el examen atento del pasaje nos revela un marco de intenciones doctrinales e ideológicos de las que nuestro Inca no pudo sustraerse: la remota gentilidad habría practicado el canibalismo; por lo tanto, sus descendientes -contemporáneos de los conquistadores de primera horallevan esa huella y deben ser "purificados" a través de la evangelización. Su ingreso a la historia depende de su aceptación del cristianismo.
Este ámbito interlineal se manifiesta a lo largo de todo el texto. Sujeto a la observación rigurosa de muchos censores, y en la urgencia de obtener patrocinios que proceden de las esferas sociales y políticas más encumbradas, el Inca compone su historia condicionado por las imposiciones coyunturales e, incluso, biográficas. Requiere la aceptación de quienes pertenecen, por sangre y cultura, a la vertiente hispánica, por lo que a cada instante declara oblicuamente sus lealtades. En los pasajes referidos a los usos gastronómicos del Imperio -que son abundantes, sobre todo en los dos últimos libros-, el registro se amolda a otros propósitos, por cuanto lo que expone ahora Garcilaso ya no es un período de barbarie, sino de civilización:

Con estas frutas, y aun por la principal dellas, conforme al gusto de los indios, pudiéramos poner el condimiento que echan en todo lo que comen -sea guisado, sea cozido o asado, no lo han de comer sin él-, que llaman uchu y los españoles pimiento de las Indias, aunque allá le llaman axi, que es de nombre del lenguaje de las islas de Barlovento; los de mi tierra son tan amigos del uchu que no comerán sin él, aunque no sea sino unas yervas crudas. Por el gusto que con él reciben en lo que comen, prohibian el comerlo en su ayuno riguroso, por que lo fuesse más riguroso, como en otra parte diximos (3).

Una descripción aparentemente trivial -el fruto llamado uchu o aji- no refleja, en absoluto, una Era de "carnicerías" y " gentilidad"; por el contrario, los indios, en una nueva fase de esa historia que aspira a dejar atrás la idolatria, hacen gala de capacidad para la sofisticación culinaria. Los naturales acompañan todos sus alimentos con ese fuerte condimento, una de las marcas más caracteristicas de la actual cocina peruana. En términos generales, para el Inca no existen diferencias insalvables entre esos nuevos súbditos de la corona española y los europeos, que también cultivan una especial predilección por realzar los sabores -o bien, disfrazarlos-. 


\section{2}

Trescientos años más tarde, ya en plena Era republicana, otro escritor emblemático de la literatura peruana incorpora a sus textos numerosas referencias a los alimentos. Es evidente que el largo transcurrir de tres siglos ha condicionado un tratamiento diferente del asunto en dicho autor, que no es otro que Ricardo Palma. Sus Tradiciones Peruanas se encuentran, efectivamente, saturadas de información acerca de las costumbres gastronómicas del pasado reciente, asi como de etapas históricas más distantes. Sin embargo, pese a las justificadas divergencias de tiempo, espacio y mentalidades, entre el Inca y Palma subsisten aspectos comunes que son, para nuestro propósito, muy ilustrativas.

En primer lugar, ambos pretenden brindar un panorama histórico de impronta totalizadora -actitud mucho más acusada en el Inca que en Palma, quien es menos sistemático-; en segunda instancia, los dos escritores han sido testigos, cuando no partícipes, de acontecimientos trascendentales para la formación de la nacionalidad.

Garcilaso, por ejemplo, presenció el ocaso del viejo imperio, la guerra entre conquistadores y la instauración de los basamentos coloniales. Palma, por su parte, nació pocos años después de la Independencia y, por lo tanto, vivió su infancia y adolescencia entre convulsiones caudillistas y la anarquia que sacudirian al pais durante sus cuarenta primeros años de vida. De algún modo, los dos autores constituyen la encarnación y la sintesis de las edades que les tocó vivir: el primero representa el estado germinal; el segundo, la consolidación del proceso cultural iniciado en el siglo XVI.

En tercer término, tanto el Inca como Palma construyen un relato singular de la historia: investigan, seleccionan materiales apropiados y reconstruyen el pasado a la medida de sus intereses y propósitos. El cusqueño lleva a cabo su tarea desde los horizontes del humanismo renacentista, pero confesional; el limeño parte del proyecto librepensador nacido de la modernidad ilustrada y burguesa que sirviera de nutriente ideológico a la Revolución francesa, a fines del siglo XVIII. Cada uno es el punto culminante de una manera de encarar la historia como "construcción imaginaria". Pero lo que en el Inca es idealización utópica, en Palma aquello se transforma, más bien, en ataques sutiles contra una serie de instituciones y usos sociales que no habian fenecido con la Independencia, sino que eran prolongación de las estructuras virreinales.

Autores como Mariátegui y Salazar Bondy (4) no han pasado por alto al gran autor en dos libros esenciales. El último de los mencionados acusa a Palma de haber creado, pese a su espíritu liberal, un estupefaciente literario que mezcla la verdad con la mentira. Lo que el gran autor de Lima la Horrible parece no comprender cabalmente es ese espíritu transgresor y lúdico que emana de las Tradiciones como edificación literaria.

Al final de la "Segunda Serie", Palma incluye el texto "Con dias y ollas venceremos". Este relato evidencia con creces la exploración de los territorios gastronómicos, no con un fin documental, como sucede en los Comentarios Reales, sino con decidida una intención ironizante y satírica, propia de la idiosincrasia criolla. La referencia a los hábitos alimenticios, en forma de inventario, se intercala en una historia acerca del general José de San Martín, acantonado en Huaura, y sumamente preocupado por encontrar un medio de comunicación eficaz con los simpatizantes de la causa libertadora. La detallada lista de predilecciones alimenticias aparece después de una digresión sobre los pregones de los viejos tiempos, a propósito de las ollas que un indio viejo lleva a la casa de Francisco Javier de Luna Pizarro. En ellas viajan mensajes secretos destinados a los patriotas:

Lima ha ganado en civilización; pero se ha despoetizado, y dia por dia por día pierde todo lo que de original y típico hubo en sus costumbres. Yo he alcanzado esos tiempos en los que parece que, en Lima, la ocupación de los vecinos hubiera sido tener en continuo ejercicio los molinos de masticación llamados dientes y muelas. Juzgue el lector por el siguiente cuadrito de cómo distribuian las horas en mi barrio, allá cuando

(4) Los dos escritores, tanto en Siete ensayos de interpretación de la realidad peruana como en Lima, la Horrible, respectivamente, dedican pasajes importantes a Palma. 
yo andaba haciendo novillos por huertas y murallas, y muy distante de escribir tradiciones y dragonear de poeta, que es otra forma de matar el tiempo o hacer novillos (5).

Para el tradicionista, es una realidad innegable que la modernidad arribó para quedarse, pero ese advenimiento -como buen librepensador, lo celebra- ha traido como consecuencia que las costumbres se transformen. Ya en tiempos de Palma, ciudadanos de su generación experimentaban ese contraste entre el presente y el pasado, que habia quedado en una suerte de limbo sicológico. Después, asistimos al célebre pasaje que, en tono de registro, da cuenta de la condición sibarita del limeño de otros tiempos, cuando el paso de las horas estaba determinado por la aparición de algún vendedor de suculentas viandas (6):

La lechera indicaba las seis de la mañana. La tisanera y la chichera de Terranova daban su pregón a las siete en punto.

El bizcochero y la vendedora de leche-vinagre, que gritaba ja la cuajaditaj, designaban las ocho, ni minuto más ni minuto me$\operatorname{nos}(\ldots)$

(...)A las siete de la noche pregonaban el caramelero, la mazamorrera y la champucera.

A las ocho el heladero y el barquillero.

Después de este cuadro de costumbres, articulado a la manera de un desfile con perfiles carnavalescos (7), Palma retorna al curso del relato, que narra, como ya lo hemos comentado, las peripecias de San Martín en su búsqueda de un medio seguro para el envio de mensajes a los patriotas. El tema gastronómico, en este caso, ha servido de materia prima para enhebrar una tradición dentro de la tradición. Es una estrategia sutilmente escogida por Palma en numerosos pasajes de su obra.

La intromisión de esos personajes, que pertenecen una ciudad que ya habia dejado de existir y que son convocados a propósito de una reflexión nostálgica, no solo funciona como una

(5) PALMA Ricardo Tradiciones peruanas Tomo I. Libreria Internacional del Peru S A. Lima, 1951, p. 386

(6) PALMA, Ricardo Ob cIt p 386

(7) En el Libro de Buen Amor del Arcipreste de Hita-cumbre de la literatura medieval española- hay un episodio similar, pero se trata de un desfile de alimenlos En Gargantua y Panlagruel, de Francois Rabelais (siglo XVI) las hiperbollicas referencias sobre la comida parecen continuar esa noble tradición literaria. tregua suspensiva respecto a la narración principal, sino que, por si misma, se erige como breve crónica de una Lima donde el sensualismo y los placeres mundanos son elementos tan inseparables de aquella, como las intensas manifestaciones de una fe católica reducida a un conjunto de fórmulas y rituales oscurantistas.

En la vieja Ciudad de los Reyes, los extremos parecen tocarse: la humana y natural tendencia a los apetitos del cuerpo coexiste con una visión represiva y culposa de la religión. Dicha combinación engendra una doble moral. Palma es consciente de ello y aprovecha la mínima oportunidad para enrostrárselo al habitante de la Aldea.

\section{3}

Una perspectiva algo diferente del asunto puede sondearse en los relatos de Abraham Valdelomar, a quien se atribuye, por consenso crítico, la fundación de la narrativa moderna en el Perú. Nacido en el puerto sureño de Pisco, se formó intelectualmente durante los últimos amagos del siglo XIX. Su reconocimiento literario -meritorio, pese a que alentó su propio mito a través de mohínes pseudoaristocráticoscoincide con la muerte de Palma, acacecida en 1919. Ejerció con brillantez el oficio de periodista en diversos medios de su época. Tal hecho afirmó su enorme influencia en la élite ilustrada, al convertirse en una versión criolla del "árbitro de la elegancia", personaje de vieja data en corrillos sociales y artísticos.

Valdelomar publicó varias colecciones de relatos. Destacan, como ejemplo de su poética, el libro titulado originalmente El caballero Carmelo (1918). Siete de esos relatos han sido reunidos en la sección "Cuentos Criollos" del tomo II de las Obras Completas, -editadas por Petro-Perú bajo la dirección de Ricardo SilvaSantisteban-. La característica central de algunas de estas narraciones es la evocación de un mundo provinciano y apacible, que el autor describe desde la visión de un adulto abrumado por la nostalgia de una niñez o adolescencia ya remotas en el tiempo. Ese tono prevalece en el célebre cuento "El caballero Carmelo", así como en "El vuelo de los cóndores" y en "Los ojos de Judas", donde la historia, generalmente, es na- 
rrada en primera persona por un personaje -niño o adolescente- que participa de los hechos o es testigo de ellos.

En el primer relato aludido -la historia de un gallo de pelea-, la recuperación de la memoria no podría efectuarse sin la mención de los sabores y olores que constituyen referentes inmediatos en el vasto horizonte de la mentalidad infantil. El hermano mayor, recién llegado al hogar paterno después de muchos años de alejamiento, constituye el marco para la irrupción de ese universo:

Sobre la mesa estaba la alforja rebosante; sacaba él, uno a uno, los objetos que traía y los iba entregando a cada uno de nosotros. ¡Qué cosas tan ricas! ¡Por dónde había viajado! Quesos frescos y blancos, envueltos por la cintura con paja de cebada, de la Quebrada de Humay; chancacas hechas con cocos, nueces, mani y almendras; frijoles colados, en sus redondas calabacitas, pintadas encima con un rectángulo del propio dulce, que indicaba la tapa, de Chincha Baja; bizcochuelos, en sus cajas de papel, de yema de huevo y harina de papas, leves, esponjosos, amarillos y dulces; santitos de piedra de Guamanga tallados en la feria serrana; cajas de manjar blanco, tejas rellenas, y una traba de gallo con los colores blanco y rojo.(8)

Para el personaje innominado que narra la historia en la primera persona del plural, el hecho de contemplar los comestibles constituye una verdadera revelación sobre al ancho mundo que él imagina, pero que aún le es vedado debido a su corta edad. El hermano mayor, cuando entrega los obsequios a cada uno de sus familiares, también les brinda una porción de horizontes y lugares no demasiado apartados en términos geográficos (poblaciones aledañas a Pisco o la ciudad de Huamanga -Ayacucho-), aunque sí en los parámetros de una imaginación en estado puro, no domesticada por la experiencia.

En el fragmento citado, los objetos con valor meramente ornamental o de culto (las efigies de santos) y aquellos que cumplen una función práctica (el aparejo para el gallo que el via-

8 VALDELOMAR, Abraham. "El caballero Carmelo", en Obras Completas. T.II; Lima, Ediciones Copé, 2000; pp.135-136 jero obsequia a su padre) se han mezclado, sin orden de prevalencia, con los dulces y bocadillos que forman parte sustancial de la esfera familiar y doméstica reconstruidas por el narrador.

En otro pasaje, la descripción de las comidas se inserta en el marco de un ambiente festivo. Se celebran las Fiestas Patrias en San Andrés, localidad cercana a Pisco. Para el narrador, sin embargo, esa atmósfera de celebraciones ostenta signos trágicos, puesto que el gallo llamado Carmelo, ya entrado en años, combatirá contra un congénere mucho más joven y dotado.

Llegamos a San Andrés. El pueblo estaba de fiesta. Banderas peruanas agitábanse sobre las casas por el día de la Patria, que alli sabían celebrar con una gran jugada de gallos a la que solían ir todos los hacendados y ricos hombres del valle. En ventorrillos, a cuya entrada había arcos de sauce envueltos en colgaduras, y de los cuales prendian alegres quitasueños de cristal, vendian chicha de bonito, butifarras, pescado fresco asado en brasas y anegado en cebollones y vinagre. El pueblo los invadia, parlanchín y endomingado cono sus mejores trajes. Los hombres de mar lucian camisetas nuevas de horizontales franjas rojas y blancas, sombreros de junco, alpargatas y pañuelos anudados al cuello (9).

Todo hace suponer que se vivirá una jornada de esparcimiento al aire libre, con la población atenta a su espectáculo favorito. Incluso, la aparición de platos típicos, en esa suerte de feria, enfatiza el tono de jolgorio y despreocupación propio de los feriados y aniversarios que suelen marcar las existencias provincianas. Pero ello contrasta con el drama interior y silencioso de los personajes, conscientes de que los mejores años de Carmelo ya son parte del pasado. Incapaces de desafiar la autoridad paterna, acompañan al gallo en su última y absurda batalla -pactada por el orgullo del padre, más que por un criterio acorde con la realidad-.

En el cuento "El vuelo de los cóndores", el eje de la historia es nuevamente la recuperación de la infancia. En esta ocasión, el narrador ofrece marcas de identidad biográficas más de-

9 VALDELOMAR, Abraham. Ob cit, p.142 
finidas que en "El caballero Carmelo". El escenario es Pisco, a fines de la década del 80 del siglo XIX. Ahora, el contexto queda constituido por la llegada de un circo a la plácida población costera. El suceso quiebra la rutina y la quietud de la esfera familiar. El núcleo de la historia es la idilica relación entre el narrador una pequeña artista, encargada del acto más arriesgado en todas las funciones. Como ya había ocurrido en el anterior relato, los usos gastronómicos son parte sustancial del bullicio y de la agitación previas a un espectáculo. Ahora, la descripción de las viandas deviene más extensa:

Llegamos por fin al pueblo y poco después al circo. Estaba éste en una estrecha calle. Un grupo de gentes se estacionaban en la puerta que iluminaban dos grandes aparatos de bencina de cinco luces. A la entrada, en la acera, había mesitas, con pequeños toldos, donde en floreados vasos con las armas de la patria estaba la espumosa blanca chicha de maní, la amarilla de garbanzos y la dulce de bonito, las butifarras, que eran panes en cuya boca abierta el aji y la lechuga ocultaban la carne; los platos con cebollas picadas en vinagre, la fuente de escabeche con sus yacentes pescados, la causa, sobre cuya blanda masa reposaba graciosamente el rojo de los camarones, el morado de las aceitunas, los pedazos de queso, los repollos verdes y el pisco oloroso, alabado por las vendedoras...(10)

La proliferación de los platillos más representativos de la culinaria marítima concluye en puntos suspensivos, creando la sensación de que la lista es interminable y como si el espacio resultara muy pequeño para dar cuenta precisa de su abundancia. La aparente despreocupación del narrador, embelesado por lo llamativo de los productos, preludia -lo mismo que en "El caballero Carmelo"- un suceso trágico (el accidente de Miss Orquidea, quien caerá del trapecio). La narración finaliza con la melancólica despedida entre el personaje principal y la pequeña trapecista, cuyo barco se pierde en la lejania.

\section{4}

Culminamos nuestro periplo por estos mares con la Poesía, que no podría estar ausente de una auténtica incursión en los predios del condimento y del sabor. Figuras como Neruda y Vallejo concedieron especial atención al tema, sobre todo el primero, quien dedicó por lo menos dos poemarios a celebrar las glorias de los vegetales (Odas elementales y Nuevas odas elementales). El peruano, por su parte, alude en muchas ocasiones a las viandas, especialmente en los poemas de Los heraldos negros que giran en torno del hogar y de la infancia. Pero también aparecen escuetas referencias en Trilce y en Poemas humanos.

En la poesía peruana del siglo $\mathrm{XX}$, un significativo número de creadores, partiendo de estéticas y motivaciones personales, se han apropiado del tema. Uno de ellos es Arturo Corcuera (1935), autor de una extensa y celebrada obra. El libro Prosa de Juglar (1992) incluye el poema "Alabanza de las comidas". Este largo texto -del cual solo transcribiremos un fragmento-, estructura un viaje a través de la historia culinaria del Perú en un registro laudatorio y épico:

Las mismas manos negras y afiladas que le arrancaron ritmos al bongó, a la conga, al tambor, a la marimba, sazonaron los sabores, pusieron en ebullición todas las sangres, picaron las tripitas, tasajearon las menudencias, cortaron el camino a las patitas andariegas, en rodajas trozaron a la afligida cebolla (más humedecidos los ojos que los de viuda pobre o novia plantada en el altar con los crespos hechos), esparcieron cereales, el perejil, los vapores aromáticos de la hierbabuena, hicieron de la cocina un madrigal, un gran concierto, un acto de amor bien condimentado (encandilando los carbones al rojo vivo) con toda la malicia y los menjunjes aprehendidos en un fatigoso trajinar. ¿Qué es el anticucho si no un corazón atravesado por una pena?(...)11 
El eco prosaico de estos versos no debilita, en absoluto, la intención de enhebrar un gran elogio a los actores de esa "historia secreta", es decir, una crónica de seres perdidos en el anonimato y el tráfago del tiempo.

El simil entre el arte musical y la culinaria no podria ser más oportuno: las manos de origen africano, oprimidas por la esclavitud, son capaces de crear ritmos y sonidos asombrosos con el concurso de atávicos instrumentos de percusión. Al mismo tiempo, son hábiles para ejecutar un "concierto" culinario, haciendo uso de ingredientes disimiles o modestos, en principio (las menudencias de las reses o los cereales), pero que encuentran su significado y valor en el acto mismo de la preparación. Este, como la creación poética o artistica, tiene algo de mágico.

Pese a la pésima calidad de los elementos, destinados solo a la mesa de los sirvientes o de los esclavos -el grado más bajo de la consideración social-, subsiste una fuerza, fruto del instinto de supervivencia, que logra transformar esa materia áspera en una "obra" plena y compleja, como son todas las elaboraciones humanas de envergadura. Es el amor a la vida en toda sus instancias quien, finalmente, permite que los esclavos traduzcan en "madrigales", "conciertos" o "poemas" aquello que, en su estado germinal, pertenece a la esfera del vientre, a las "cosas del cuerpo".
El anticucho, marca fundamental de la actual cocina de la costa, es una poderosa alegoría de ese hombre condenado a no gozar de los fueros de la libertad, pero que, en medio de esa dura supresión de un derecho natural, aún logra asombrarse ante el hecho de que el mundo, el universo, sea bello y horroroso; elevado y vulgar; luminoso y oscuro, como si su sino fuese la oscilación eterna entre dos polos.

\section{BIBLIOGRAFÍA}

CORCUERA, Arturo.

1992 Prosa de Juglar. Ignacio Prado Pastor/Editor; Lima,

DE LA VEGA, Inca Garcilaso.

1985 Comentarios Reales de los Incas. Banco de Crédito del Perú; Lima,

PALMA, Ricardo.

1951 Tradiciones Peruanas.T.I. Librería Internacional del Perú S.A., Lima.

VALDELOMAR, Abraham.

2000 Obras completas, T.II. Ediciones Copé; Lima, . 